\title{
A questão do tempo originário na leitura heideggeriana da imaginação transcendental kantiana e sua relação com a meta de Ser e Tempo
}

The question of originary time in Heidegger's reading of Kant's transcendental imagination and its relation to the scope of Being and Time

Alexandre Guedes

guedestayor@hotmail.com

(Universidade Federal de Goiás, Goiás, Brasil)

\begin{abstract}
Resumo: Na preleção, Kant e o problema da metafísica (1929), Heidegger diz que Kant, na segunda edição da Crítica da Razão Pura (1787), elimina a possibilidade de investigação do tempo originário como sendo a unidade das duas fontes do conhecimento (sensibilidade e entendimento), visto que a imaginação transcendental havia deixado de ter o destaque fundamental contido na primeira edição da obra (1781). Assim, nosso objetivo com o presente artigo é entender como, na leitura heideggeriana, a imaginação transcendental pode ser tomada como fonte do conhecimento a priori e, também, como, a partir dela, Heidegger tematiza a questão da temporialidade (Temporalität).
\end{abstract}

Palavras-chave: tempo originário; eu penso; imaginação transcendental; ontologia fundamental.

\begin{abstract}
In the lecture, Kant and the Problem of Metaphysics (1929), Heidegger says that Kant, in the second edition of the Critique of Pure Reason (1787), eliminates the possibility of investigating the originary time as being the unity of the two sources of knowledge (sensibility and understanding) since the transcendental imagination had ceased to have the fundamental prominence contained in the first edition of the work (1781). Thus, our aim is to understand how the transcendental imagination can be taken as a source of a priori knowledge and also, how, based on it, Heidegger thematizes the question of the temporality (Temporalität).
\end{abstract}

Keywords: originary time; I think; transcendental imagination; fundamental ontology.

\section{Introdução}

$\mathrm{Na}$ introdução da preleção, Kant e o problema da metafísica (1929), Heidegger (1986, p.11) traça seu objetivo: interpretar a Crítica da Razão Pura como fundamentação da metafísica; o que culminará no problema de uma ontologia fundamental. Como é sabido, em Ser e Tempo, o projeto da ontologia fundamental parte da analítica existencial do Dasein como caminho preparatório para, em última análise, tematizar a questão sobre a relação doadora de sentido entre ser e tempo. 
Na preleção ora tratada, Heidegger é claro ao dizer que ontologia fundamental é a analítica ontológica da essência finita do ser humano, a que irá preparar o fundamento de uma metafísica conforme a natureza do homem (idem, ibidem). No entanto, tais posições não parecem ser heterogêneas. 0 tema da ontologia fundamental, enquanto analítica da natureza do homem, está mais apropriado ao contexto kantiano, uma vez que, como veremos, visa apontar para o que faltou ao criticismo: alcançar a questão do Ser pelo viés da temporialidade (Temporalität). ${ }^{1}$ Nesse sentido, tanto Ser e Tempo, quanto Kant e o problema da metafísica, conduz o leitor ao mesmo ponto: a questão da comum pertença entre o tempo e o ser.

Fundamentar a metafísica, para Heidegger, significa investigar as condições de sua possibilidade, provar a solidez de seu fundamento (Heidegger, 1986, p. 12). Quanto a isso, Kant (2012, p. 19, A XII) dizia-se orgulhoso da Crítica da Razão Pura, a pedra de toque responsável por trazer à metafísica o rigor necessário, visto que a razão se equivoca ao projetar um conhecimento que excede às faculdades humanas (idem, p. 17, A VII). Essa falta de rigor fez com que a "rainha de todas as ciências" passasse por uma época de descrédito, sendo compreendida como um campo de diversas e infindáveis discussões (idem, ibidem). A Crítica, portanto, traz o rigor científico à metafísica, uma vez que coloca as certezas subjetivas sob análise, eliminando todo dogmatismo equivocado. Com a sua fundamentação e a consequente eliminação dos equívocos da razão, segundo Kant, a metafísica não dará mais espaço para o ceticismo, nem margem à especulação superficial e despropositada (idem pp. 39, 40, B XXXIV, B XXXVII).

Mas para colocar a metafísica no patamar de uma ciência, faz-se mister entender como se dá, antes de tudo, o conhecimento das coisas. Segundo Kant, apesar de nosso conhecimento começar com a experiência, ele não surge apenas dela (idem, p.45, B1). Os dados sensíveis da experiência são compreendidos como uma indispensável parte de uma complexa função do entendimento humano. Essa complexidade diz de nossa estrutura cognoscível que é, ao mesmo tempo, independente da experiência e causa necessária dela. Kant se refere a essa estrutura por meio das faculdades $a$ priori.

A seguir, abordaremos os traços fundamentais dessas faculdades do conhecimento humano presentes na Crítica da Razão Pura, que culminarão no tema

\footnotetext{
1 Vale ressaltar que Fausto Castilho não traduz Temporalität por temporialidade, mas sim, por temporalidade (Heidegger, 2012a, p. 91). Seguimos, quanto ao termo, a interpretação de Marco Casanova na tradução da preleção, Os problemas fundamentais da fenomenologia, que fora ministrada no verão de 1927, na Universidade de Marburgo, a qual Heidegger afirma ser a reelaboração da terceira seção de Ser e tempo (Heidegger, 2012b, p. 7, nota de rodapé de número 1). Marco Casanova faz diferença entre os termos temporialidade (Temporalität) e temporalidade (Zeitlichkeit) (idem, pp. 332, 333). Grosso modo, a temporialidade se refere ao horizonte próprio à investigação do Ser em geral, ao passo que a temporalidade se refere ao sentido do ser do Dasein como existência finita.
} 
A questão do tempo originário na leitura heideggeriana da imaginação transcendental ...

do esquematismo transcendental, ponto crucial para entendermos a relação de Kant com a questão da temporialidade.

\section{A relação do eu penso com a imaginação transcendental em Kant.}

Para Kant, os objetos são dados por meio da sensibilidade através de intuições e são pensados no entendimento através de conceitos (2012, p. 71, B 33). A explicação de como nos referimos a priori aos objetos por meio de conceitos é tarefa da dedução transcendental; a investigação das intuições puras como princípios da sensibilidade a priori, por sua vez, é o âmbito da estética transcendental. Por estas vias, sensibilidade e entendimento, que, segundo Kant, podemos adquirir conhecimento (idem, p. 96, B 74).

Ao contrário do que se pode pensar no senso comum, as condições dessa sensibilidade são independentes da experiência. As intuições puras, espaço e tempo, são necessárias às sensações, uma vez que toda interação com os objetos se dá mediante a um espaço, o qual nos permite representá-los como estando "fora de nós", bem como, mediante a um tempo, sem o qual até mesmo aos dados sensoriais seriam apenas um aglomerado caótico de impulsos indefinidos advindos de influências externas. Ademais, o espaço e o tempo não são abstraídos como algo externo, semelhante à ideia, ou à imagem de uma árvore, por exemplo; antes, o espaço e o tempo são o fundamento e a possibilidade de nossa experiência. Por isso, também são chamados de formas da intuição. O espaço, como forma do sentido externo, e o tempo, como forma do sentido interno (ou seja, o modo como nos percebemos como sujeitos pensantes). Por esta razão "o tempo é a condição formal a priori de todos os fenômenos em geral” (Kant, 2012, p. 81, B 50). Quer dizer, mesmo que o espaço seja a condição formal a priori dos fenômenos externos, uma vez que deles temos representações, tais fenômenos estão atrelados a um estado mental que, por sua vez, estão fundamentados no estado interno do sujeito e, portanto, estão submetidos ao tempo como condição imediata do fenômenos internos (nossa alma) (idem, p. 82, B 51).

Grosso modo, é neste sentido que Kant afirma que nosso conhecimento surge de duas fontes fundamentais da mente: intuição e conceitos (idem, p. 96, B 74) e diz "pensamentos sem conteúdo são vazios, intuições sem conceitos são cegas" (idem, p. 97, B 75). Isto porque os conceitos puros do entendimento não podem mostrar um objeto a priori (idem, p. 122, B 120) e precisam estar relacionados a uma intuição que, por sua vez, é o modo como nos relacionamos imediatamente com os objetos afim de termos conhecimento (idem, p. 71, B 33-34). No entanto, as representações advindas da sensibilidade precisam se juntar às advindas do entendimento para, assim, termos condições de nos referirmos aos objetos como fenômenos e, desta 
maneira, termos conhecimento em geral. Tal atividade é para Kant da ordem da síntese (idem, p. 112, B 101-103).

Segundo Kant, síntese é "a ação de somar diferentes representações umas às outras e abarcar a sua diversidade em um conhecimento" (idem, p. 112, B 103) A síntese que resulta em um conhecimento é denominada de síntese geral (idem, ibidem) e a síntese do diverso que não é dado pela experiência, mas sim, a priori, como nas relações fundamentadas no espaço e tempo, Kant denomina de síntese pura (idem, ibidem).

Em B130, Kant diz que o ato de ligar, a síntese, pressupõe, por sua vez, uma atividade operada espontaneamente pelo sujeito, uma autoatividade. Assim, "o conceito de ligação traz consigo, além do conceito do diverso e da sua síntese, também o conceito de sua unidade" (Kant, 2012, p. 129, B 131). Essa atividade de ligação é um trabalho do entendimento (B 135) o qual coloca as representações sob a unidade da apercepção, o que Kant diz ser o princípio maior do conhecimento humano (idem, ibidem). Sem essa unidade, de acordo com Kant, não teríamos a possibilidade de pensar em algo ou, por mais que tivéssemos uma intuição, tal representação não equivaleria a nada para nós. Através da consciência dessa atividade de unificação indispensável para o conhecimento, temos a possibilidade de nos representarmos como um sujeito que pensa, um eu penso consciente das representações em geral (idem, pp. 129, 130, B 132-133).

Porém, por mais que possamos ter consciência dessa atividade do sujeito de colocar para si representações, de acordo com o criticismo kantiano, não podemos afirmar que temos, a partir disso, conhecimento de nós mesmos enquanto coisa em si. No entanto, enquanto fenômeno, podemos dizer que temos "conhecimento" de nós mesmos (B 156). Em outras palavras, apesar do eu penso não poder ser tomado como objeto de uma experiência possível, no sentido de um objeto externo, enquanto autoconsciência pode ser entendido como objeto do sentido interno (B 405). Kant relaciona a ideia de objeto externo e interno com a ideia de corpo e alma (Kant, 2012, p. 302, B 400).

O sentido interno é a forma da intuição. Mesmo sem conter nenhuma intuição determinada, pela ação da imaginação transcendental (B 154), a faculdade responsável por representar um objeto mesmo sem sua presença na intuição, o sentido interno possibilita-nos representarmos a nós mesmos como, por assim dizer, um objeto interno. Desta maneira, podemos nos representar, segundo Kant, como um eu penso (Kant, 2012, p. 140, B151-152).

A autoconsciência, portanto, estando em conformidade com o sentido interno, ação da imaginação, é a expressão disso que aparece em nós mesmos como pura autoatividade (B 158). Como se sabe, o modo como as coisas aparecem para nós tem a ver com as regras das faculdades puras de nosso juízo pelas quais podemos nos 
referir aos objetos apenas enquanto fenômenos e, portanto, não como coisas em si (noúmeno). O eu penso neste sentido expressa a ação de determinação de nossa existência como um fenômeno, o que significa dizer que a autointuição, baseada no tempo como sua condição a priori, permite à espontaneidade do entendimento nos conceituar como um eu pensante e, desse modo, nos entendermos como existência (Kant, 2012, p. 144, B 158-159).

Contudo, por mais que, até aqui, tenhamos visto o eu penso como ação do entendimento sobre a imaginação na determinação do fenômeno da existência, na leitura heideggeriana da Crítica, nos deparamos com passagens que permitem entender a imaginação transcendental não como apenas uma faculdade a serviço do entendimento. Isto é, a imaginação transcendental, salientada pela interpretação do esquematismo transcendental, na visão de Heidegger, indica o tempo originário não somente como fundamento da sensibilidade, mas também, como fundamento do eu penso. Ou seja, até mesmo o entendimento toma por base o tempo originário, uma vez que ele, o tempo, se mostra como um horizonte indispensável a todo conhecimento puro, bem como, indispensável a toda representação em geral.

\section{A leitura heideggeriana do esquematismo transcendental e sua relação com o escopo de Ser e Tempo}

A imaginação transcendental, conforme Heidegger indica na Crítica, em A 154, não é uma faculdade entre a sensibilidade e o entendimento, mas sim, uma faculdade fundamental responsável pela unidade das referidas faculdades e pela a possibilidade de toda transcendência ${ }^{2}$ necessária ao conhecimento em geral (Heidegger, 1986, p. 118, 119).

Por “conhecimento em geral”, Heidegger (1986, p. 18) se refere ao conhecimento ontológico (metaphysica generalis), o qual se distingue da investigação do ser de um ente específico (metaphysica specialis). Esta divisão, segundo o pensador, está fundamentada na concepção da metafísica como visão de mundo cristã. Nela, a totalidade dos entes é compreendida e subdividida em Deus, natureza e homem, e seus respectivos campos de conhecimento são a teologia, a cosmologia e a psicologia (metaphysica specialis). Em última análise, o objetivo dessa metafísica especial, como ressalta Dubois, é a salvação do homem:

O que significa a interpretação cristã do mundo? A divisão do ente em criado e incriado, e no seio do primeiro, a singularidade do homem para quem está em causa sua salvação e a eternidade de sua alma, em sua relação com Deus. A natureza, o homem (do ponto de vista da salvação e da liberdade e da imortalidade de sua alma) e Deus. Com isso se terá reconhecido aquilo que se torna objeto para uma "metafísica especial" (2004, p. 81).

2 Transcendência, neste contexto, significa a possibilidade transcendental do conhecimento, ou seja, indica o fundamento a priori de toda a experiência. 
A ontologia (metaphysica generalis), neste prisma, por não se ater a nenhum ente específico, busca conhecer o que é comum a todos os entes, isto é, busca reconhecer uma unidade inteligível que possa estar de acordo com a especificidade de cada ente. 0 conhecimento ontológico, portanto, é aquele que dispensa previamente a influência dos entes particulares na busca pelo conhecimento prévio, o qual pode ser aplicável a todo tipo de conhecimento específico. Em termos kantianos, isso equivaleria a investigação da possibilidade do conhecimento puro, que dá condições para toda e qualquer experiência do objeto.

Desta maneira, de acordo com Heidegger, a metafísica (metaphysica specialis) depende da ontologia enquanto validação da possibilidade de um conhecimento rigoroso, que, estando no fundamento da metafísica, permitirá ao homem, ao fim e ao cabo, tratar do que realmente interessa segundo a visão de mundo cristã: a salvação da alma e a vida eterna (Heidegger, 1986, p. 18).

No entanto, para os propósitos de nosso trabalho, o mais importante é visualizar que, para Heidegger, a fundamentação da metafísica depende do aval da ontologia como prova e condição do conhecimento anterior a toda experiência. Isso, para ele, tem a ver com o problema dos juízos sintéticos a priori e com a Crítica da Razão Pura de modo geral (idem, p. 23).

Voltando à leitura heideggeriana da imaginação em Kant, vemos que, ao formar imagens, no sentido amplo do "figurar-se, idear, inventar, fazer juízos, ter ideias, etc." (Heidegger, 1986, p. 114), a imaginação dá o aspecto do que não está propriamente "ante aos olhos" (idem, ibidem). Porém o seu caráter criador não pode ser confundido com a atividade de um possível intelecto divino que, ao mesmo tempo que pensa, cria determinado ente. A imaginação somente cria o aspecto, ou a forma de um objeto possível (idem, p. 115). Ela forma previamente o aspecto do horizonte de objetividade como tal, antes da experiência do ente (idem, p. 116). Isto implica que, uma vez que toda experiência só é possível, como vimos na seção passada, devido às faculdades a priori, a imaginação, sendo o horizonte de objetividade, juntamente com a sensibilidade e o entendimento, compõe tanto o fundamento de todo o conhecimento, como a possibilidade de toda experiência (Heidegger, 1986, p.119).

De fato, Kant afirma na primeira edição da Crítica, em A 115, que o sentido, a imaginação e a apercepção são fundamentos a priori do conhecimento subjetivo, algo que destoa com o que o próprio Kant disse na segunda edição, em B 74, onde afirma que o nosso conhecimento advém de duas fontes fundamentais: sensibilidade e o entendimento. Heidegger aponta nessa mudança de enfoque do papel da imaginação, a impossibilidade de perceber que o eu penso e o tempo são o mesmo (Heidegger, 1986, p. 163), algo que vem à tona com a adequada tematização da questão da imaginação por meio do esquematismo transcendental (idem pp. 139; 168), o qual 
mostra a essência criadora da imaginação de modo originário (idem, p. 116), uma vez que mostra a imagem pura do tempo (idem, p. 117).

$\mathrm{Na}$ Crítica, em B 179, podemos ver que o esquema se diferencia da imagem, apesar de ser um mero produto da imaginação. O esquema é a representação da possibilidade de se conceituar através da determinação fornecida pela imagem. Por exemplo, Kant diz que podemos representar a imagem do número cinco por pontos consecutivos (.....), mas se pensamos no número cinco antes de qualquer conceito, isso seria algo como o pensamento do modo como se conceitua uma imagem. "A esta representação, pois, de um procedimento universal da imaginação para fornecer a um conceito a sua imagem, eu denomino o esquema desse conceito" (Kant, 2012, p. 176, B180).

Heidegger observa que há nisso algo conflitante. Os esquemas não são produtos do entendimento. Não obstante os esquemas serem empregados pelo entendimento, uma vez que condicionam os conceitos, eles não são produtos do entendimento, mas sim, produtos da imaginação (Heidegger, 1986, p. 132).

Como falado linhas acima, o esquematismo mostra a essência criadora da imaginação de um modo muito mais originário (Heidegger, 1986, p. 116). Por “originário", Heidegger tem em mente o termo originarius da expressão intuitus originarius, um fazer surgir (idem, p. 124). A imaginação pura faz surgir espontaneamente a intuição pura, ou seja, as “representações originárias” espaço e tempo. (idem, ibidem). Em relação a isso, Heidegger cita A 145 e B 184, onde Kant afirma que os esquemas são determinações a priori do tempo segundo regras, ou seja, os esquemas são produtos da imaginação. 0 uso pelo entendimento das determinações a priori do tempo pela imaginação transcendental, Heidegger aponta como sendo o esquematismo transcendental (idem, p 95).

Desta maneira, o esquematismo transcendental revela o uso do entendimento das determinações das representações originárias que a imaginação faz surgir espontaneamente. Assim, diz Heidegger, "se a imaginação transcendental como faculdade formadora pura forma em si o tempo, quer dizer, se faz surgir o tempo, não há maneira de evitar a tese já mencionada, a saber: a imaginação transcendental é o tempo originário" (idem, p. 160).

Esta interpretação permite a Heidegger entender o tempo como estrutura essencial da subjetividade e da apercepção pura, visto que, como intuição pura, ele pré-forma o aspecto do objeto e, neste sentido, é a condição de toda receptividade (Heidegger, 1986, p. 161). De acordo com sua própria essência, o tempo é afecção de si mesmo. Todavia, apesar do tempo não ser nada externo, ao modo de algo ante aos olhos, ele não deve ser pensado somente como "dentro" do sujeito. Kant diz que o tempo é "uma condição subjetiva de nossa (humana) intuição (a qual é sempre sensível, i.e., na medida em que somos afetados por objetos), e em si mesmo, fora 
do sujeito, nada é” (2012, p. 82, B 51). Heidegger vai além, e diz que o tempo é o sujeito mesmo como um todo (Heidegger, 1986, p. 160). Isto porque a afecção pura, ou autointuição de si mesmo, diz do próprio ato do tempo originário e, portanto, ambos são apenas modos de referência à mesma coisa.

Com efeito, Heidegger (1986, p. 163) entende que o tempo e o eu penso não são heterogêneos, mas são o mesmo. Ademais, diz que Kant, por mais que tenha interpretado de modo transcendental o tempo como separado do eu penso, não percebeu que, na dedução transcendental e no esquematismo, atribuiu, respectivamente ao eu da apercepção e ao tempo, os mesmos predicados: ambos são permanentes e estáveis (Heidegger, 1986, pp. 163, 164). ${ }^{3}$ Apesar de ter consciência que, de pronto, tal assimilação não aparente nada demais, reforça que estável e permanente são determinações transcendentais que dizem da imbricação tanto do eu, quanto do tempo. Quer dizer, o eu penso se refere a um eu represento e tal possibilidade de representação só é possível graças ao horizonte de objetividade que é o tempo. Em outras palavras, o referir-se puro ao eu é a referência ao aspecto puro proporcionado pela essência do tempo (idem, p. 165). Com isso, Heidegger aponta que a interpretação da imaginação transcendental indica que o tempo originário produz as duas fontes necessárias ao conhecimento, sensibilidade e entendimento, uma vez que a fundamentação da apercepção e do tempo - como afecção de si - é o tempo originário, a raiz da transcendência, a imaginação transcendental (idem, p. 167).

Portanto, de acordo com Heidegger (1986, p. 168), a segunda edição da Crítica elimina a possibilidade de se colocar o tempo originário sob investigação, visto que a mudança de foco não the permite se mostrar como fundamento do conhecimento puro. É nesse prisma que, como ressalta Dubois, a Crítica da Razão Pura se mostra como uma ontologia fundamental:

A Crítica da Razão Pura não é uma "teoria do conhecimento", uma teoria da experiência científica, mas uma ontologia fundamental. A questão da possibilidade da metafísica especial reflui portanto para a questão da possibilidade da metafísica em geral (2004, p. 82).

De fato, Heidegger desenvolve a questão do tempo no projeto de sua ontologia fundamental, tema diretriz de sua obra capital Ser e Tempo. No parágrafo sexto (Heidegger, 2012a, p. 91), Heidegger diz que era necessário uma análise ontológica da subjetividade do sujeito para que o problema do ser viesse à tona em Kant. E, como visto até aqui, tal análise, de acordo com sua interpretação da imaginação transcendental, revela o tempo originário como o fundamento da transcendência e estrutura da subjetividade. Essa análise que Heidegger acusa ter faltado em Kant é desenvolvida em Ser e Tempo sob o título de analítica existencial do Dasein. Ela

3 Confira Heidegger, 1986, p. 164. Lá, ele indica as passagens, A 144, B183 e A 182, B 225 de onde compara a mesma predicação para o eu da apercepção e para o tempo. 
conduz ao problema da temporialidade (Temporalität) como horizonte possível para se entender o Ser em geral. Ou seja, somente porque o Dasein pode compreender o seu modo de ser, i.e. sua existência como finitude por referência à temporalidade (Zeitlichkeit), ${ }^{4}$ temos condições de colocar a questão da relação de sentido do ser em geral por referência a uma temporalidade específica, a qual Heidegger (2012b, pp. 332, 333) denomina de temporialidade (Temporalität).

O objetivo maior de Ser e Tempo é a busca pela autêntica pergunta pelo sentido do Ser em geral. Somente com a sua adequada tematização, será possível o estabelecimento de uma ontologia fundamental capaz de fornecer o entendimento do Ser, tanto o aplicável aos modos de ser específicos de cada ente, como o independente das relações específicas com este. Para tanto, o projeto da ontologia fundamental pretende evidenciar a condição de possibilidade de entendimento do Ser dos entes em geral por meio de uma questão apropriada. Essa condição, em última análise, é o tempo, mais especificamente, o horizonte da temporialidade (Temporalität) que, logo no início do tratado, é posta como meta provisória (Heidegger, 2012a, p. 31), porém, páginas à frente, é assumida como a resposta pelo sentido do Ser:

a tarefa ontológica fundamental da interpretação de ser como tal compreende em si a elaboração da temporalidade do ser (Temporalität des Seins). Só na exposição da problemática da temporalidade pela primeira vez se dá uma resposta concreta à pergunta pelo sentido do ser (2012a, p. 79, parêntesis nosso).

Mas, como sabemos, Ser e Tempo não se conclui. Das duas partes previstas para compor a obra, com três seções cada, somente a primeira parte, com duas seções, foi publicada. A despeito disso, vale salientar que em uma das questões que encerram a última seção, qual seja: “Há um caminho que conduza do tempo originário ao sentido do ser?” (Heidegger, 2012a, p. 1179) está o problema do tempo originário, o qual foi identificado por Heidegger no contexto específico da Crítica da Razão Pura. Com isso, queremos salientar que, mesmo depois de Ser e Tempo (1927), o tema concernente à questão do sentido do ser em relação ao tempo permanece em Kant e o problema da metafísica (1929), ou seja, mesmo com a incompletude de sua obra capital, não podemos concluir, precipitadamente, que o projeto da ontologia fundamental foi abandonado, antes que se estabeleça uma pesquisa aprofundada nas demais obras de Heidegger posteriores ao ano de 1927.

\section{Considerações Finais}

Por mais que Ser e Tempo não cumpra o previsto quanto à interpretação do esquematismo transcendental, podemos concluir que, com a preleção Kant e o problema da metafísica, alcançamos uma satisfatória interpretação da Crítica da

4 Pois ela permite a relação do Dasein com a morte (ser-para-a-morte) por meio da estase do tempo do por vir (Zukunft). É o futuro (Zukunft) o elemento originário da temporalidade. 
Razão Pura como possibilidade de aclaramento e de tematização da questão do tempo originário em relação ao fundamento da transcendência, bem como, em relação à investigação concernente à ontologia fundamental.

Outrossim, vimos que, de fato, Kant nos mostra passagens controversas quando se compara a primeira com a segunda edição da Crítica. Isso nos chama a atenção para a possibilidade de investigarmos, na literatura secundária, possíveis explicações para tal mudança de perspectiva quanto à imaginação transcendental.

Por fim, queremos ressaltar a importância da Crítica da Razão Pura, tanto para o estudo do pensamento heideggeriano, quanto para a história do pensamento filosófico. Kant "foi o único filósofo na história da ontologia que pressentiu alguma coisa sobre essa conexão íntima entre a compreensão do ser e o tempo" (Dastur,1990, p. 37). Muito provavelmente, esse é um dos motivos pelos quais Heidegger manteve presente o pensamento kantiano em suas preleções posteriores ao ano de 1927.

\section{Referências}

Dastur, F. (1990). Heidegger e a questão do tempo. Tradução de João Paz. Lisboa: Instituto Piaget.

Dubois, C. (2004). HEIDEGGER: introdução a uma leitura. Tradução de Bernardo Barros Coelho de Oliveira. Rio de Janeiro: Jorge Zahar Editor.

Heidegger, M. (1986). Kant y el problema de la metafísica. Traducción de Gred Ibscher Roth. México: Fondo de Cultura Económica.

Heidegger, M. (2012a). Ser e tempo. Tradução de Fausto Castilho. Rio de Janeiro: Vozes.

Heidegger, M. (2012b). Os problemas fundamentais da fenomenologia. Tradução de Marco Casanova. Rio de Janeiro: Vozes.

Kant, I. (2012). Crítica da Razão Pura. Tradução de Fernando Costa Mattos. Petrópolis: Vozes.

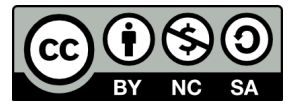

